DOI 10.37882/2500-3682.2022.01.17

\title{
ПЕВЧЕСКИЕ ХАРАКТЕРИСТИКИ И ЦЕННОСТНОЕ ВОПЛОЩЕНИЕ «НОВЫХ НАРОДНЫХ ПЕСЕН» КАК ТВОРЧЕСКАЯ ОСОБЕННОСТЬ СОВРЕМЕННОЙ МУЗЫКАЛЬНОЙ ЭПОХИ В РАЗВИТИИ КИТАЙСКОЙ КУЛЬТУРЫ
}

\section{SINGING CHARACTERISTICS AND VALUE EMBODIMENT OF "NEW FOLK SONGS" AS A CREATIVE FEATURE OF THE MODERN MUSICAL ERA IN THE DEVELOPMENT OF CHINESE CULTURE}

Zhao Meng

Summary: Folk song is an ancient art form of the Chinese people. Chinese folk songs are an important part of China's centuries-old traditional culture, the soul and symbol of the Chinese nation. The culture of Chinese folk songs is vast and comprehensive, and the content of folk songs covers science, culture, anthropology, ethics, sociology and other humanities. However, over time, folk songs undergo a transformation, as evidenced by the appearance of "New Folk Songs" in the XX century. In modern society, "New Folk Songs" became the center of public attention, and their appearance led Chinese musical creativity away from the original ancient folk songs. In the long history of the Chinese people, the artistic form of folk songs developed and was transmitted along with history. New folk songs based on traditional culture unite nationality with popularity, the modern era, and also unite the cultural and economic interests of the state into a single whole. This not only takes into account the new aesthetic psychology and the needs of people in a new era, but also many other factors in accordance with modern aesthetic standards. This article first defines folk songs, new folk songs, and then explains the general situation with the popularization of "New Folk Songs" in China. The article focuses on the popularization of folk songs, their modern interpretation and performance options with the help of modern musical instruments. The article examines the trend of transformation and adaptation of folk music into the so-called "New Folk Song", which reflects modern trends in music, understandable to the broad masses of the Chinese population.

Keywords: folk music, new folk songs, popularization of new folk songs, musical trends, music history, PRC, musical culture, traditional culture.

\author{
Чжао Мэн \\ Аспирант, Российский государственный педагогический \\ Университет им. А.И. Гериена \\ zhaomeng0819@mail.ru
}

Аннотация: Народная песня - древний вид искусства китайского народа. Китайские народные песни являются важной частью многовековой традиционной культуры Китая, душой и символом китайской нации. Культура китайских народных песен обширна и всеобъемлюща, а содержание народных песен охватывает науку, культуру, антропологию, этику, социологию и другие гуманитарные науки. Однако с течением времени, и народные песни претерпевают трансформацию, о чём свидетельствует появление в XX веке «новых народных песен». В современном обществе «новые народные песни» стали центром общественного внимания, и их появление уводило китайское музыкальное творчество от оригинальных древних народных песен. В долгой истории китайского народа художественная форма народных песен развивалась и передавалась вместе с историей. «Новые народные песни», основанные на традиционной культуре, объединяют национальность с популярностью, современной эпохой, а также объединяют культурные и экономические интересы государства в единое целое. Это не только учитывает новую эстетическую психологию и потребности людей в новую эпоху, но и многие другие факторы в соответствии с современными эстетическими стандартами.

В данной статье сначала дается определение народных песен, «новых народных песен», а затем объясняется общая ситуация с популяризацией «новых народных песен» в Китае. В статье делается акцент на популяризацию народных песен, их современную интерпретацию и варианты исполнения с помощью современных музыкальных инструментов. В статье исследована тенденция трансформации и адаптации народной музыки в так называемую «новую народную песню», которая отражает современные тенденции в музыке, понятные широким массам населения Китая.

Ключевые слова: народная музыка, новые народные песни, популяризация новых народных песен, музыкальные тенденции, история музыки, КНР, музыкальная культура, традиционная культура.
$\mathrm{B}$ результате глобальных реформ и всеобъемлющей политики открытости китайское общество претерпело значительные изменения во всех сферах жизни, и в особенности в области культуры. Материальная жизнь людей существенно улучшилась, а их духовная и культурная жизнь значительно обогатилась.

Китайская история, уходящая корнями в глубокую древность, за многие столетия обогатилась народными мотивами отразившимися в музыкальном творчестве. Народные песни берут свое начало из реального творчества и жизни трудящихся. Народные песни - это квинтэссенция национальной культуры, воплощающая национальный дух, характер, темперамент, психологию, местные обычаи и эстетическую привлекательность на- 
ции. Оригинальные народные песни в разных уголках Китая имеют давние традиции. Под влиянием современного экономического, политического и культурного фона в них проявились многие черты новой эпохи [11, c. 140].

С постепенным развитием этих характеристик новая эпоха стала приобретать «новые народные песни» с современными музыкальными характеристиками и новейшими музыкальными стилями, благодаря влиянию общества и её собственной эстетической логики, представляющей собой художественные особенности, отличные от традиционных народных песен. «Новые народные песни» имеют отличительные черты времени. Эстетические характеристики в основном включают народные напевы, популярные мотивы и влияние музыкальной моды, но среди них народные характеристики являются основными признаками новых народных песен $[5$, с.18].

\section{1. Интерпретация «новых народных песен»}

Создание «новых народных песен» имеет свое разнообразие собственные тенденции в смысле воплощения идейного замысла. Разнообразные стили произведений не могут быть в полной мере реализованы чистым народным пением. Более того, популярные и модные элементы включаются в создание современных народных песен. Многие певцы заимствовали у Запада стилистику, манеру поведения, артистические приемы, исполняя «новые народные песни». Музыкальные атрибуты, основанные на традиционном пении народных песен, включают в себя характеристики более популярной музыки, делая её более доступной и понятной. Исполнитель берет основной тон традиционных народных песен в качестве своей ведущей черты и в то же время интегрирует в него современную музыку, раскрывает личность современных людей, приближая их к реальной жизни и объединяя популярное пение в современном стиле с традиционным пением, чтобы публике было легче его принять. Таким образом, новый метод пения отражает современную моду и тенденцию к возрождению, и популяризации народных песен [9, с.154].

Традиционные народные песни представлены китайской публике через качественно новую манеру исполнения, включающую современные методы интерпретации музыки. «Новые народные песни» - это разностороннее проявление возможностей исполнителей, разнообразной тематики песен и современные возможности трансформации сцены как основы музыкально-театрального действия. Эти проявления в основном отражаются в следующих аспектах:
1. По сравнению с традиционными народными песнями, навыки пения и стиль «новых народных песен» сильно изменились.

Исполнители «новых народных песен» могут анализировать характеристики и стили песен и использовать соответствующие им методы. С улучшением способности слушателей к восприятию музыки традиционный метод пения народных песен оказался неспособен удовлетворить потребности людей. Поэтому исполнитель включает в «новую народную песню» новейший метод пения, благодаря которому песня звучит мягче и нежнее. Эти изменения позволили народной песне представить новый смысл [10, с. 42].

Первым методом является голосовой метод исполнения народных песен. Этот метод построен на основе профессиональных знаний и умений, включая дыхание, использование горла, оральный резонанс и особого способа произнесения слов.

Второй метод - это эмоции, что требуют, от певца обладания сильным чувством воспроизведения слов и мелодии. Например, при хоровом исполнении, делается упор на звуковую часть, и игнорируются эмоции, что никогда не позволит качественно исполнить певческую партию.

Причина, по которой голосу уделяется слишком много внимания, заключается в том, что возможности певца ограничены. Во время исполнения музыкальной партии вокалист всегда обращает внимание на дыхание, и готовится к переходу на высокий тон, и когда он достигается, неизбежно исчезает эмоциональная составляющая. Поэтому, «звукоэмоциональная» практика очень важна, так как привлекательность исполнения песен становится сильнее.

С современной точки зрения, когда выражаются традиционные вокальные произведения, их необходимо эффективно интегрировать в соответствии с мелодией песни или тонами текста. В процессе интеграции возникает высокий спрос на мысли и эмоции, а в процессе эмоционального выражения требуется точное знание языковых особенностей. Чтобы сохранить ясность интерпретации и позволить настроению произведения показать идеальную насыщенность необходимо реализовать правильное понимание настроения песни [13, c.135].

Третий - чувственный метод. Он зависит от того насколько у исполнителя присутствует врожденное или привитое чувство музыки и в каком объеме они могут им воспользоваться. Чувства каждого исполнителя различаются, что влияет и на то, как они подходят к исполнению той или иной песни. 
Четвертый метод - чувства ритма и интонации. Это талант. Исполнение песен требует такой основы. Хотя исполнители и не должны быть выдающимися, но они не должны быть и слабыми. От осознания и ощущения темпа, метра, тона и интенсивности, музыкальной формы и её протяженности зависит точное интонационное исполнение мелодии.

Пятый метод олицетворяет качество исполнения. В этом и есть разница между певцами-любителями и певцами-профессионалами. По сравнению с настоящим качеством по звуку, эмоциям, чувствам, ритму и интонации многие певцы-любители практически не уступают профессиональным музыкантам-исполнителям, однако разрыв заключается в качестве, так как многолетняя исполнительская практика, имеющая прочную теоретическую основу, всегда будет обладать преимуществом [1, с. 98].

\section{2. Форма аккомпанемента «новых народных пе-} сен» претерпела изменения во многих аспектах.

Вокальное сопровождение - это развивающийся метод пения «новых народных песен», а вокальный ритм аккомпанемента делает певческий голос более сильным и глубоким. Кроме того, быстрое развитие электроакустических групп, объединение национальных музыкальных инструментов и электронных музыкальных систем и программ, используемых в современной музыке, привело к замене единого оркестра, таким образом, что «новые народные песни» стали более популярными и глобализированными. «Новые народные песни», благодаря современным методам электронно-музыкальной интерпретации, становятся популярными во всем мире, так как их понимают, принимают и любят широкие массы слушателей [12, с. 138].

\section{3. Одной из важных особенностей «новых народ-} ных песен» является визуальная выразительность.

Во время выступления на сцене исполнителям необходимо выполнять больше координационных задач. Эмоциональная атмосфера требует разного освещения, яркого или темного, общего или индивидуального, точечного стационарного или динамического в сочетании с использованием мультимедийных технологий, новых медиа, большие экраны показывают публике совершенно новую современную сцену для «новых народных песен» $[8$, с. 9].

\section{2. Певческие характеристики «новых народных песен» (язык, тембр, Аыхание и $\Delta$. р.)}

1. Языковые особенности исполнения «новых народных песен».

Именно из-за разнообразия языков в разных странах и регионах стили пения всех стран мира являются богатыми и красочными. Особенности языка определяют стили вокальной музыки разных национальностей.

Народная песня - это вокальная музыкальная культура, которая формировалась и развивалась шаг за шагом в процессе длительного исторического процесса и жизни народа, импровизации и деятельности, в том числе и «сарафанного радио», передачи песен из «уст в уста». Очень важную роль в исполнении народных песен играют разные национальности, местные языки, и этнические наречия. Для хорошего исполнения народных песен необходимо полностью понимать языковые особенности национальностей или регионов, к которым они принадлежат. Только так можно ярко интерпретировать диалектные характеристики и народные обычаи «новых народных песен». Поскольку происхождение народных песен неразрывно связано с диалектами, то для того, чтобы петь аутентичные народные песни, необходимо владеть местным языком [4, с. 130].

2. Характеристики дыхания при исполнении «новых народных песен».

Для повышения качества исполнения народных песен, наиважнейшим является научное использование дыхательного метода исполнения народных песен. Атмосфера пения традиционных народных песен требует глубокого дыхания, полной памяти, гибкости дыхания. Пение «новых народных песен» наследует традиционные методы дыхания народных песен и включает особые характеристики певческого дыхания, такие как повышение дыхания, остановка дыхания, и закрытие дыхания.

В применении разных способов певческого дыхания «новых народных песен» используется дыхательный метод Bel canto, в то время как при исполнении традиционных народных песен в основном используется грудное дыхание, а не брюшное дыхание. Bel canto фокусируется на использовании комбинированных методов грудного и брюшного дыхания, которые делают голос более полным, округлым и плавным [2, с. 187].

\section{3. Тембровые характеристики исполнения «но-} вых народных песен»

Во время исполнения народных песен вокалист может использовать разные тембры, чтобы выразить различные коннотации и эмоции произведения. При исполнении «новых народных песен» из-за различий между разными этническими и региональными певческими стилями различается и использование тембра.

Тембр отражает характеристики голоса каждого, и в мире не существует идентичного тембра. Тембр людей может измениться из-за возраста или по другим при- 
чинам, и это изменение нельзя контролировать. Невозможно сделать свой голос таким же, как у кого-то другого. Например, при исполнении народных песен в северной провинции Шэньси певец должен контролировать движения своего горла, чтобы певческий тон был более локальным [14, с. 77].

В определенной степени китайский язык является одним из важных факторов национальной вокальной музыкальной культуры Китая, а также обладает уникальными фонологическими характеристиками нации. Например, четкий, концентрированный, звонкий и т.д.

В процессе звучания народная вокальная музыка более склонна к разнообразию тембров, которые не только отражают отличительные характеристики, но и особые атрибуты.

Зарубежная вокальная музыка сильно отличается от традиционной китайской вокальной музыки и поддерживает стандартизированный резонанс в фиксации тембра. Поэтому в процессе интеграции передачи вокальных данных и требований, предъявляемых к исполнителю, традиционная музыкальная культура должна уделять внимание тембру и звуку [6, с.225].

\section{3. Шенность «новых народных песен»}

\section{1. Культурная ценность.}

«Новые народные песни» в совокупности представляют культурную ценность страны. «Новые народные песни» Китая отражают основную культуру страны в определенный период, что является важным элементом времени в «новых народных песнях». Культурная ценность «новых народных песен» отражается в национальных особенностях и в наследии традиционной культуры в «новых народных песнях». Известно, что опера и народная музыка произошли от народных песен. В то же время местная опера и народная музыка способствовали развитию народных песен, добавляли новые элементы в народные песни и постепенно превращались В «новые народные песни» [15, с. 64].

\section{2. Социальная и мировая ценность «новых народ- ных песен» в новую эпоху.}

«Новые народные песни» в основном созданы для того, чтобы их могли слушать в современном ключе, так как они наиболее близки к современной обыденной жизни людей. «Новые народные песни» не только обогащают развлекательную жизнь, но также служат обществу и способствуют его гармоничному развитию. Артисты используют уникальные способы исполнения «новых народных песен», чтобы выразить свои чувства. Восхваляя в песнях хорошую жизнь, они могут выразить и своё не- довольство, тем самым отражая жизнь всего общества.

В связи с быстрым развитием науки и технологий сегодня глобальная интеграция экономики и культуры стала неизбежной тенденцией развития.

Народные песни как представители китайской национальной музыки будут играть незаменимую историческую роль в процессе глобализации народной культуры. Народные песни имеют ярко выраженные национальные особенности, но их содержание и выражение слишком единообразны, а их конкурентоспособность немного слабее, чем у западной музыки [3, с. 44].

Поэтому необходимо в полной мере использовать все преимущества китайской национальной музыки, основанной на собственном художественном стиле народной песни, интегрировать и использовать передовые методы, и выражения западной современной музыки. Музыковеды Китая, исполнители, не только могут сохранить сущность народных песен, но и в определенной степени должны противостоять вторжению чужих культур. В то же время необходимо повышать конкурентоспособность народного китайского песенного искусства в мире и продвигать народные песни на мировую арену. «Новые народные песни», которые активно внедряются, не только сохраняют культурные и художественные характеристики самих традиционных народных песен, но и лучше переносят и наследуют древние художественные формы китайской культуры. Кроме того, безграничный характер «новых народных песен» отражает космополитический характер «новых народных песен».

Международное распространение народных песен в новую эпоху соответствует развитию времени. Это позволяет международному художественному сообществу лучше понять китайскую национальную музыкальную культуру.

Чтобы сделать народные песни новой эры более удобными для международного распространения, в процессе создания фольклорные песни новой эры максимально принимают некоторые современные элементы и используют новый метод аудиовизуальной интерпретации для самовыражения. Отношение к международному распространению произведений является новаторской концепцией, отличной от традиционной эпохи $[7$, с. 6].

Поскольку китайские народные песни выходят на мировую музыкальную сцену, в новую эпоху, не следует недооценивать улучшение их художественно-эстетической ценности.

\section{Зак^ючение}

Таким образом, развитие народных песен в новую 
эпоху идет в ногу со временем. Наследие «новых народных песен» усиливает своё влияние благодаря вливанию элементов моды. Популярность «новых народных песен» уходит корнями вглубь истории китайской нации.

Популяризация «новых народных песен» может иметь определенный защитный эффект на оригинальные народные песни, но в то же время неизбежно разрушение, и музыканты должны осознавать масштабы этого. Причина, по которой китайские музыканты уделяют так много внимания оригинальным народным песням, заключается не только в том, что они являются культурным достоянием великой страны, но и потому, что песни поддерживают общую тенденцию развития китайской культуры в новом столетии. Необходимо сохранить «корни народного искусства» для процветания и популяризации традиционной культуры и местных народных песен.

Социальная среда для создания и распространения народных песен в новую эпоху изменилась. Поэтому, создавая народные песни, необходимо соответствовать новой социальной ситуации с одной стороны и соблю- дать закон распространения и развития народных песен с другой стороны, и постоянно вводить новые идеи для создания народных песен.

В то же время важно иметь справедливое понимание и суждение о важности создании народных песен в новую эпоху. Следует избегать многих актов повторяющегося творчества, а также следует исключить некоторые грубые адаптации или даже создание так называемых «фиктивных» традиционных народных песен с бессмысленными текстами к ним.

Использование заимствования и методов музыкальной трансформации совместно с современными мультимедийными технологиями в музыке - это концептуальный путь развития, которым необходимо следовать при создании народных песен в новую эпоху. Таким образом, совершенно очевидно, что «новые народные песни» могут обеспечить постоянный источник вдохновения и демонстрировать разнообразие элементов национальной вокальной музыки Китая.

\section{ЛИТЕРАТУРА}

1. Вэй Хуэйли. Дилема выживания и путь развития народных песен Хуэйчжоу в контексте глобализации. - Пекин: Издательство Современная музыка, 2019. - № 6. - 98-99 c.

2. Гао Ин. Возникновение и популярность народных песен династии Хань с точки зрения музыкальной социологии. - Пекин: Издательство Современная музыка, -2016 . - № 19.- 87-88 c.

3. И Лиюань. Социальная среда и тенденции распространения китайских народных песен в новую эпоху. - Пекин: Издательство Художественная критика, $-2019 .-43-45$ c.

4. Конг Минся. Анализ эволюции китайских народных песен. - Чифэн: Издательство Журнала Университета Чифэн (издание по философии и философским наукам, - 2019. - № 40. - 130-132 с.

5. Ма Лицзюнь. 06 эстетической привлекательности и ценностной ориентации «Новых народных песен» в новую эру. - Пекин: Издательство Северная музыка, - 2016.- С.19.

6. Пан Ли. Последствие преподавания традиционной музыкальной культуры в вокальной музыке в высшем профессиональном образовании. -Пекин: Журнал профессионального колледжа Цзямусы, - 2019. - № 10. - 224- 226 с.

7. Хэ Жуйцзюань. Путь к возрождению китайских народных песен в контексте новой эры: унаследование и развитие китайских народных песен из оригинального проекта по обучению талантов экологическим народным песням. - Нанкин: Издательство China Art News № 3. - 2017. - C.16.

8. Цзи Цзюньцзоань. Современное эхо ханьских народных песен. - Пекин: Издательство Современная музыка, - 2017. - №12. - 8-10 с.

9. Цзинь Яо. Пересечение традиции и современности. Анализ характеристик нового музыкального языка народных песен и расширение инновационной ценности. - Пекин: Издательство Music Creation, - 2017. - № 7. - 153-155 с.

10. Цзян Линьфан. 0 характеристиках и причинах появления новых народных песен. - Шанхай: Популярная литература и искусство, - 2016. - С. 48.

11. Цзян Хуэйминь. 0 певческих характеристиках и ценностном воплощении «новых народных песен» в новую эру. - Пекин: Издательство Art Review, 2017. - №8. - 139-142 c.

12. Чжан Вэйпан. Происхождение и развитие народной песни. - Пекин: Издательство Современная музыка, - 2015. - 136-138 с.

13. Чжан Цзянь, Чжан Чжибинь. Техника и индивидуальность в вокальном музыкальном искусстве, а также о реформе и инновациях в преподавании вокальной музыки в колледжах и университетах. - Пекин:Журнал Сианьской консерватории музыки, - 2014. № 2. - 134-138 с.

14. Чжуан Цюнь. Анализ развития китайских народных песен.- Пекин: Дом драмы, - 2021. - №16. - 77-78 с.

15. Чжан Юэ. В контексте новой эры создание песен должно «открывать» новые темы - супором на «Симпозиум по созданию песен новой эры».- Пекин: Издательство Детская музыка, - 2018. - С.112

(c) Чжао Мэн (zhaomeng0819@mail.ru). 